\title{
Challenges and Innovation in Steel Wire Production
}

\author{
Lotfi Chabbi ${ }^{1, a^{*}}$, Stephan Hasler ${ }^{1, b}$, Hans Roelofs ${ }^{1, c}$ and Heiko Haupt-Peter ${ }^{1, d}$ \\ ${ }^{1}$ Swiss Steel AG, Emmenweidstrasse 90, CH-6020 Emmenbrücke, Switzerland \\ alchabbi@swiss-steel.com, 's shasler@swiss-steel.com, hroelofs@swiss-steel.com, \\ hhaupt@swiss-steel.com
}

Keywords: Steel wire manufacturer, steel development, material concepts, innovative strength, process innovation, product quality, product innovation

\begin{abstract}
Products and manufacturing processes of long-product producers are subject to constantly changing requirements, characterized by increasing demands on product quality and the efficient use of resources in production, combined with permanent cost pressures. For these reasons steel wire producers must constantly improve their innovation capacity to be able to meet increasing customer demands more flexibly and more efficiently. This awareness has been anchored at Swiss Steel AG, part of the Schmolz + Bickenbach Group, for many years and leads to more and new solutions in all corporate divisions.

This article focuses on practical examples from the areas of process and product innovation. It discusses options for and the potentials and challenges of meeting current and future market needs.

The successful implementation of new solutions requires an in-depth understanding as well as the application of knowledge throughout the entire process chain from development, production, sales to further processing and actual use of a product. The technical challenges are addressed as well as the opportunities presented when new approaches are sought.
\end{abstract}

\section{Introduction}

The steel wire industry is a dynamic environment. The requirements for products and manufacturing technologies are constantly increasing and becoming ever more demanding. The focus of the efforts is the sustainable guaranteeing of competitiveness as the globalization of business increases. In this context, flexibility, efficiency, and above all innovative capacity become ever more important.

The requirements profile for product quality has gradually been expanded over time to include the following aspects: attractive prices, short delivery times, high delivery reliability, high flexibility and efficient technical support and consulting [1]. Attractive margins can no longer be achieved today with conventional production of standard steel grades. Because of the more demanding, changing parameters, standard solutions will frequently not be enough in future to make a profit. What will increasingly be needed are solutions developed specifically for a given customer or application.

Meeting these targets requires establishing a comprehensive innovation process (Fig. 1) like the one in place at Swiss Steel AG for many years. The result of this process, among other things, is that new solutions have regularly been developed in close cooperation with active customers.

This includes, for example, inclusion engineered steel which has improved machinability or high-strength steel for automotive components subjected to dynamic loads. Ongoing innovation projects guarantee that this success story continues. 


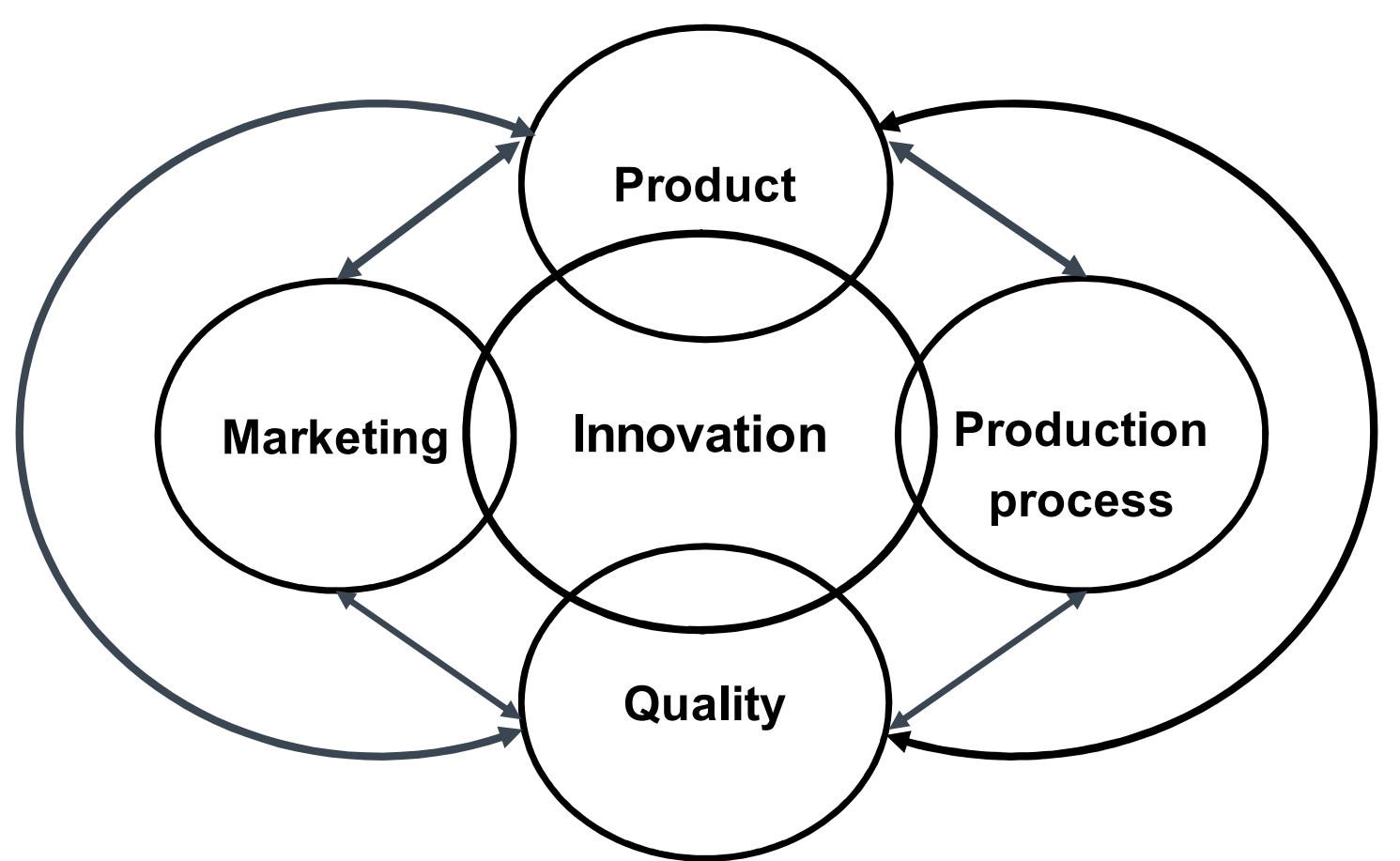

Fig. 1. Areas of innovation for the production of sophisticated long products

\section{Process innovation in the area of product development}

To be able to offer sustainable innovative solutions, in addition to developing new material concepts, the existing manufacturing and testing processes should constantly be optimized and expanded. This affects the secondary metallurgy treatment processes, micro-alloy techniques and continuous casting and rolling.

If the hot-rolling process for wire is considered, product quality primarily the wire microstructure and the mechanical properties are the result of numerous metallurgical processes that occur simultaneously or sequentially and are interdependent [2-4]. The interactions between the rolling process parameters and the development of the steel wire properties or between the material and the main system units are very complex. Consequently, vast knowledge of the areas of metallurgy, forming technology and processing until the product is finished is necessary to develop innovative solutions.

From a technical standpoint, thermomechanical treatment is becoming ever more important to steel wire production. Due to a recent and intensive current increase in knowledge in this area, this rolling process has developed into a wide range of technologies (Fig. 2). The challenge is to select the right technology to meet customer requirements and future market developments and integrate them in the existing rolling mill.

The trend in cold forming, for example, toward shorter processing of wire into finished parts without intermediate heat treatment (spheroidizing annealing) and/or final quenching and tempering has continued for over 20 years and is today well established.

In one specific case, the customer requested processing of a MnB steel $(0.30 \% \mathrm{C} ; 0.20 \% \mathrm{Si}$; $0.85 \% \mathrm{Mn} ; 0.006 \% \mathrm{~B}$ ) without spheroidizing annealing first. This was intended to use less energy and fewer work steps in the processing chain, making the entire process more economical (Fig. 3). 


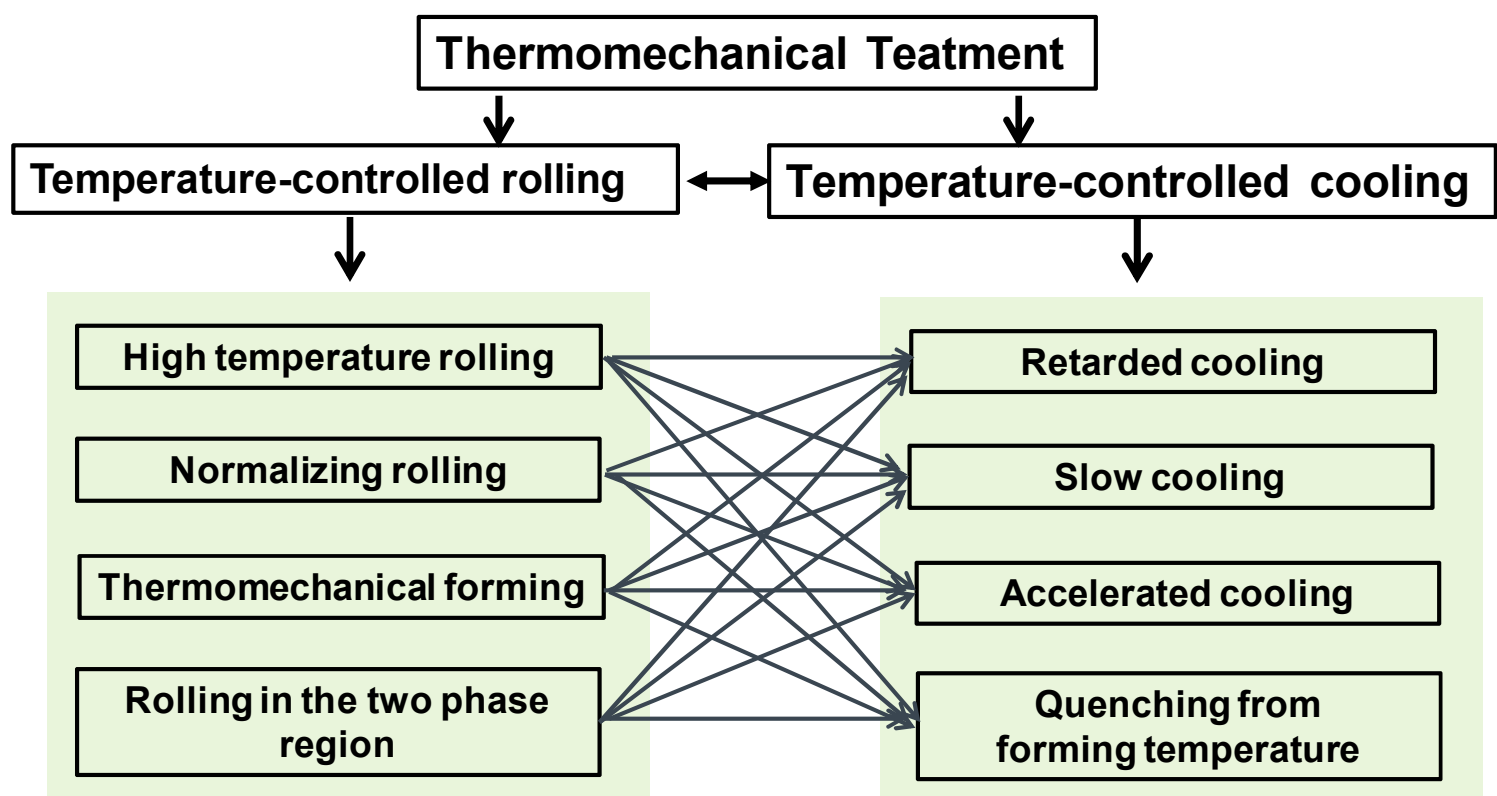

Possibilities for temperature-controlled rolling at Swiss Steel AG: $21.0-64.0 \mathrm{~mm}$

Fig. 2. Thermomechanical technologies used during wire rolling

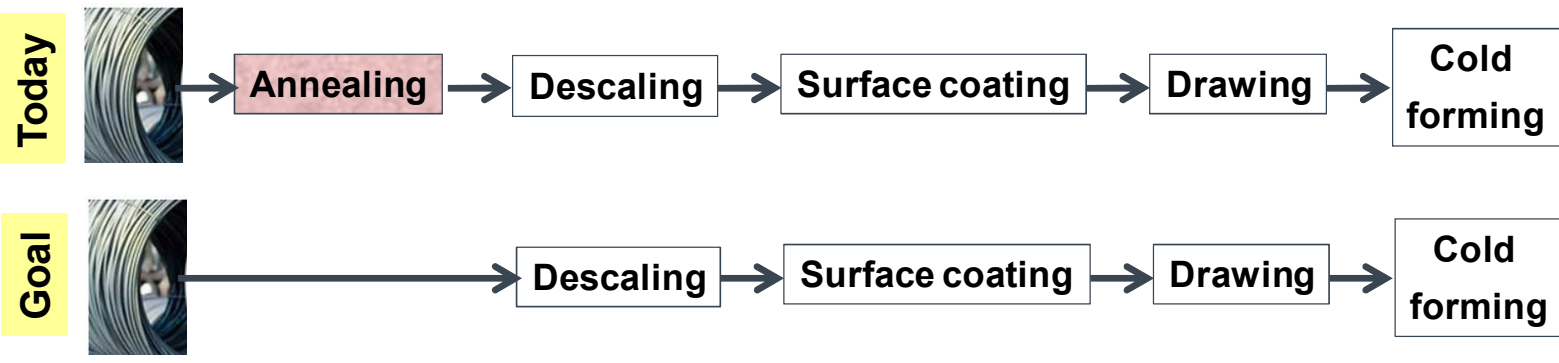

Fig. 3. Production of MnB steel without spheroidizing (GKZ annealing) / aim of the project

The customer process and steel wire application were analyzed first. As a result, the customer specification for this specific application was able to be redefined in close cooperation (Table 1).

Table 1. Production of MnB steel without spheroidizing annealing / Project specifications

\begin{tabular}{|c|c|c|c|c|}
\hline \multirow{2}{*}{$\begin{array}{c}\text { Dimension } \\
{[\mathrm{mm}]}\end{array}$} & \multicolumn{2}{|c|}{$\begin{array}{c}\text { Maximum Tensile Strength } \\
\mathrm{Rm}_{\max }[\mathrm{MPa}]\end{array}$} & \multicolumn{2}{c|}{$\begin{array}{c}\text { Minimum Reduction of area } \\
\mathrm{Z}_{\min }[\%]\end{array}$} \\
\cline { 2 - 5 } & Customer Specification & Standard & Customer Specification & Standard \\
\hline$\leq 11.0$ & $\mathbf{6 0 0}$ & 570 & $\mathbf{5 0}$ & 63 \\
\hline
\end{tabular}

In a second phase, the basic properties and special features of the steel, for example, in regard to transformation behavior were intensively studied. This was then followed by an adjustment of the target rolling process parameters in regard to the required product quality.

In this case, the challenge was to meet the customer needs despite the limited options of temperature-controlled forming in this dimensional range. As a comparison, the results following thermomechanical rolling from tests conducted externally were also consulted.

Ultimately, through the specific selection of the heating conditions, managing the rolling speed and above all the development of suitable cooling strategies for the Stelmore line, the required mechanical properties were successfully achieved (Fig. 4). The material was easily processed by the customer to the final product. 


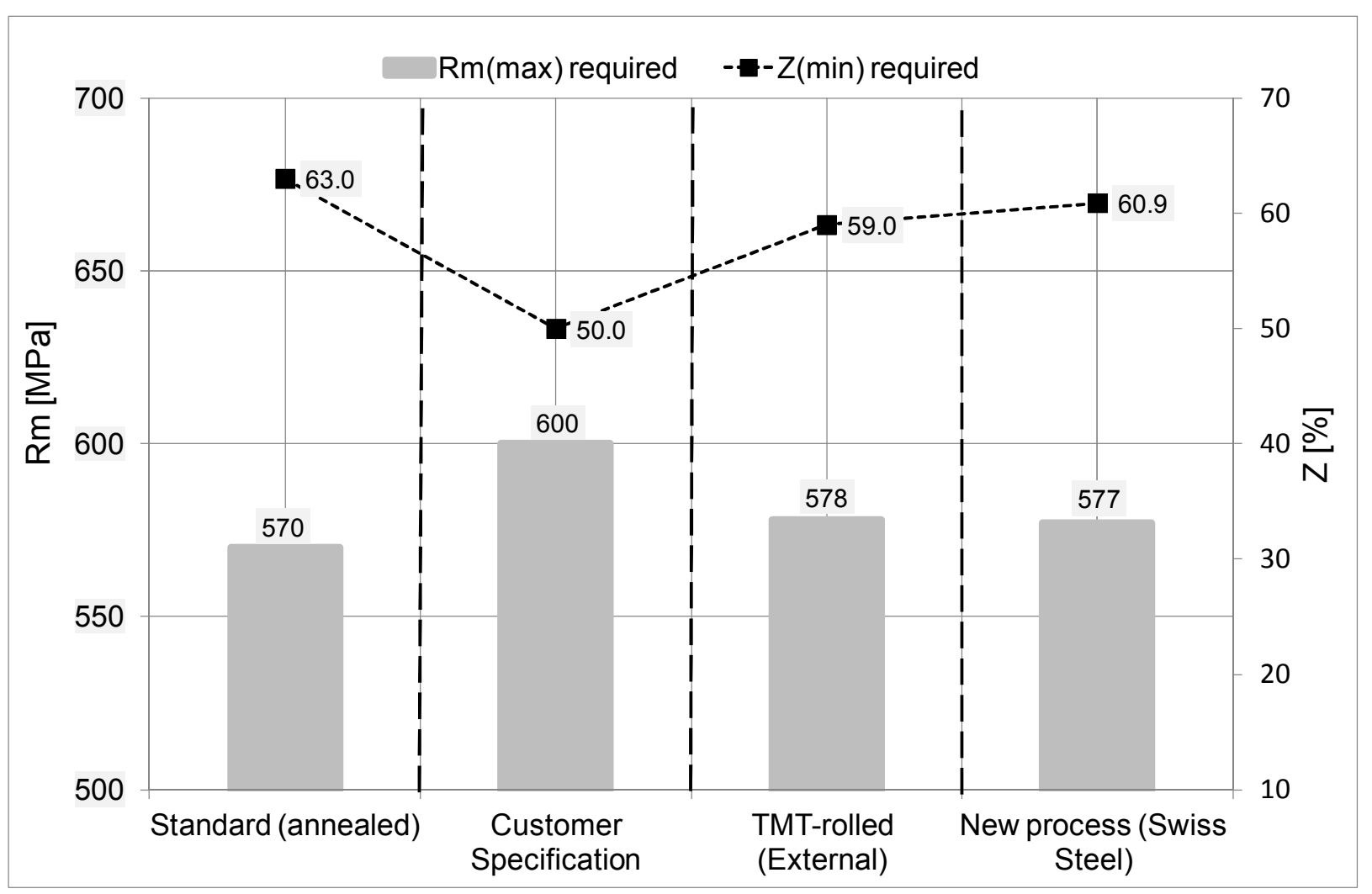

Fig. 4. Properties of $11.0 \mathrm{~mm}$ rolled wire of a MnB steel in different qualities

(TMT: Thermomechanical treatment)

\section{Product innovation}

Gradually maximizing existing technical options in the further development and production of standard products already established on the market, as shown in the aforementioned example, is absolutely necessary. Through the use of new material concepts with existing technology, the windows for processes and properties for further processing, e.g. by the customer, can be optimized and/or decisively expanded.

One example of a newer and innovative Swiss Steel product development for the area of cold forming is the micro-alloyed bainitic steel Swissbain-7MnB8 (1.5519) already anchored in the standard (prEN 10263-2). Because of its outstanding properties largely characterized by good formability combined with high strength, Swissbain-7MnB8 is the "state-of-the-art" for the production of high-strength steel components (strengths of up to $>1000 \mathrm{MPa}$ ) by means of cold forming without heat treatment (Table 2) [5-6]. Use of this interesting alternative to quenched and tempered steel can considerably shorten process chains and thus lower manufacturing costs.

Table 2: Mechanical properties of Swissbain-7MnB8 in the as-rolled condition (diameter range: 7 to $40 \mathrm{~mm}$ )

\begin{tabular}{|c|c|c|c|}
\hline $\begin{array}{c}\text { Yield stress } \\
\mathrm{Rp}_{0.2}[\mathrm{MPa}]\end{array}$ & $\begin{array}{c}\text { Tensile strength } \\
\mathrm{Rm}[\mathrm{MPa}]\end{array}$ & $\begin{array}{c}\text { Elongation at fracture } \\
\mathrm{A} 5[\%]\end{array}$ & $\begin{array}{c}\text { Reduction of area } \\
\mathrm{Z}[\%]\end{array}$ \\
\hline $500-700$ & $650-850$ & $>17$ & $>55$ \\
\hline
\end{tabular}

Another aspect that cannot be ignored is also the better environmental footprint (lower use of resources and fewer $\mathrm{CO}_{2}$ emissions) compared to the use of quenched and tempered steel across the entire value-add chain, culminating in the final application. This is particularly true for steel produced using the LD process. Lightweight components also improve the carbon footprint.

By reducing vehicle weights, their use can save considerable amounts of fuel and thus $\mathrm{CO}_{2}$. Moreover, overall less steel must be produced and processed for assemblies and components using material and geometric lightweight construction criteria. Figure 5 shows the maximum $\mathrm{CO}_{2}$ savings 
in the production of a lightweight nut M14x1.5 at the company Hewi G. Winker with a 20\% weight reduction by using Swissbain-7MnB8 from Swiss Steel AG instead of a LD-based quenched and tempered steel from the EU. The savings are based on the use of 216 tons of steel per year for orderbased manufacturing within the scope of series production.

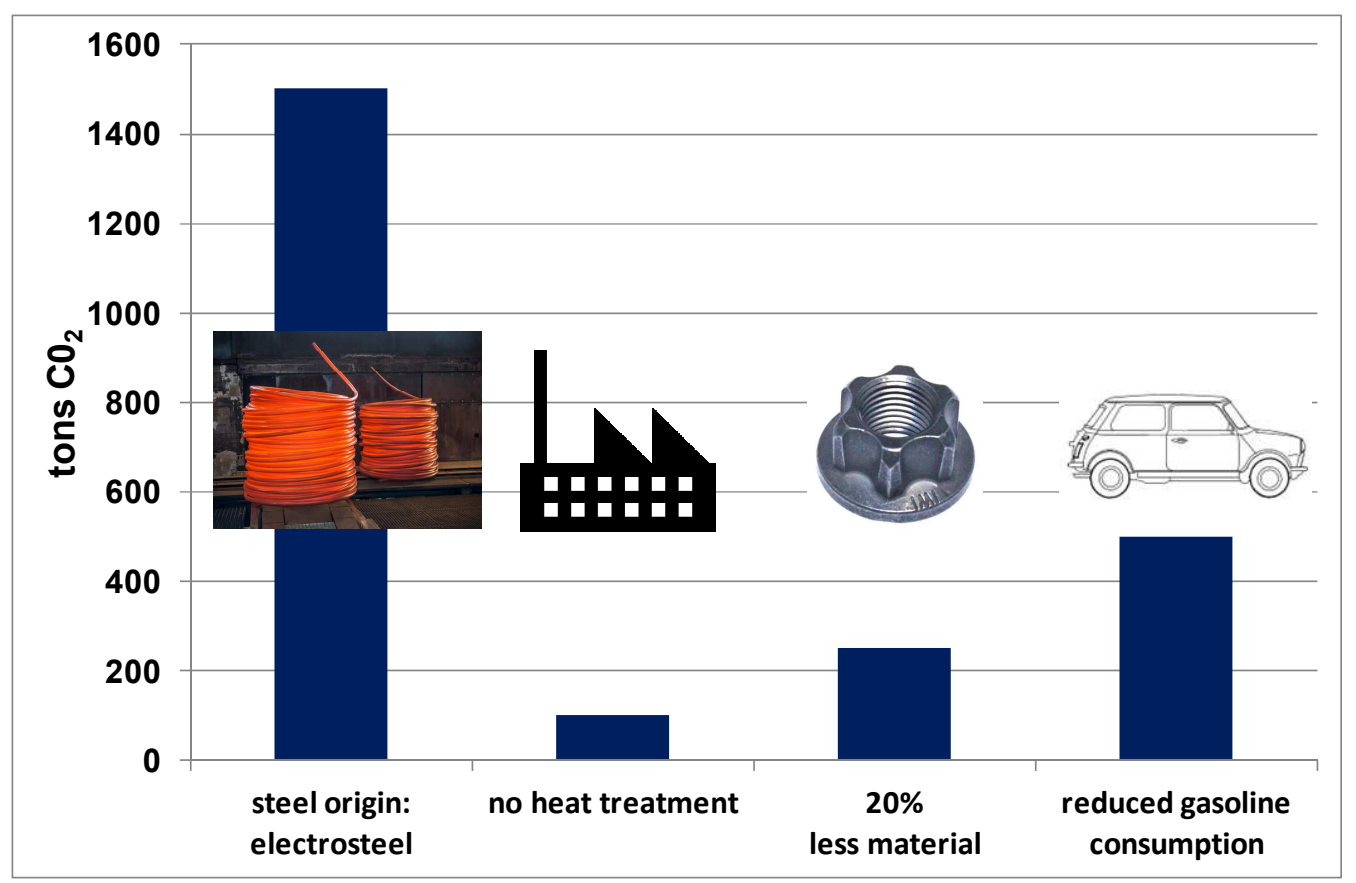

Fig. 5. Maximum $\mathrm{CO}_{2}$ savings in the production and use of a lightweight nut $\mathrm{M} 14 \times 1.5$ from the company Hewi G. Winker [7]

The Swissbain-7MnB8 product gives cold forgers an added value and new opportunities. Specifically in conjunction with issues such as lightweight construction and ever stricter environmental requirements, this material can be both an economically as well as an environmentally interesting option for future (product) developments in the area of cold forming.

New and more demanding material concepts and products can not only be developed and technically implemented, but also successfully realized in specific applications, which is often associated with additional challenges.

Innovative steel producers must thus also be able to support new developments to get steels like Swissbain-7MnB8 into series production. In addition to in-depth knowledge of material science and an understanding of the industry's entire manufacturing chain, what is needed is the close cooperation with partners and innovative marketing approaches.

An example, both of exemplary development cooperation between a steel producer and a customer as well as of a successful market launch of a new product is the new development "Lightweight nut" from the company Hewi G. Winker GmbH \& Co. KG in Spaichingen, Germany [8]. The weight of the nut can be reduced up to $30 \%$ by optimizing the design. Ultimately, the Swissbain-7MnB8 solution for Hewi G. Winker is a solution that has considerable advantages in regard to the use of energy throughout the entire process chain, from the production of the alloy and the required use of material to the elimination of energy-intensive treatment steps to the phase of use and the lifetime of the vehicle, and is also even much more cost-effective.

Another steel development still in an early stage is graphitic steel 50SiB8. Graphitized steels are a past development, and they are said to perform excellently in machining processes. They are considered as environmentally friendly alternatives to widely used toxic $\mathrm{Pb}$-alloyed steels.

Although graphite inclusions are supposed to generate in-situ lubrication, the mechanism and the corresponding optimum working zone are not very clear. To investigate the real potential of graphitic steels, an 80-tons industrial heat was produced and annealed for graphitization. Figure 6 
gives an overview of the frictional behavior of reference steels $11 \mathrm{SMnPb} 30,16 \mathrm{MnCrS5} \mathrm{Pb}$ and graphitic steel $50 \mathrm{SiB} 8$ at different cutting speeds. The maximum uncertainty in friction measurements is $\pm 4 \%$. When the cutting speed increases, the curves approach a value of 0.2 in dry conditions, which corresponds to a semi-solid frictional regime as assumed by Neugebauer et al. [9] and Rech et al. [10]. Steel 50SiB8 exhibits the lowest friction coefficients in a wide range of cutting speeds, proving the in-situ lubrication of graphite. Additional machining tests reveal the realistic potential of graphite to replace lead if the hardness of the compared steels is similar [11].

Present R\&D activities at Swiss Steel are twofold: on one hand, the graphitization process should be shortened by optimizing hot rolling parameters to improve the cost effectiveness of this steel concept. On the other hand, future applications are under investigation. Whereas the substitution of standard leaded low-carbon free-cutting steels is out of range due their extremely low production costs, other leaded steels such as case hardened or quenched \& tempered steels could potentially be replaced by graphitized steel. The low ultimate tensile strength of graphitized steel also allows a high degree of cold deformation. Cold heading applications are conceivable. Last, but not least, the in-situ lubrication of graphitized steel makes it an attractive material for use in applications such as bearings, where lubrication plays an important role.

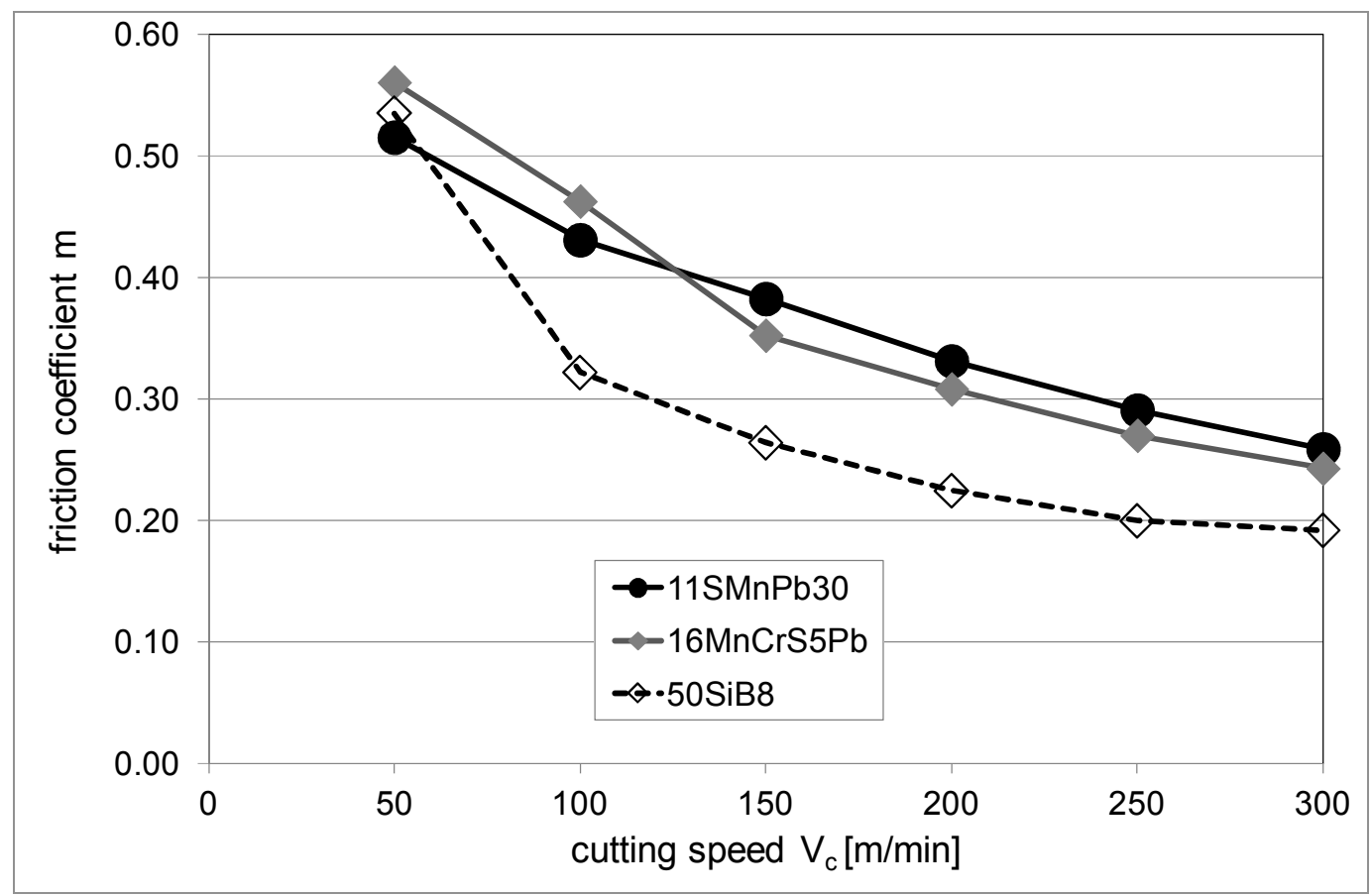

Fig. 6. Friction coefficients as measured

\section{Summary}

The steel industry today is characterized by constant cost pressure combined with increasing demand for product quality and simultaneous compliance with more and more stringent ecological and normative requirements. Maintaining the economic margins for standard products is becoming more and more difficult. Consequently, solutions are needed that are specific to a particular market, application and customer.

These targets can only be met by establishing a comprehensive innovation process. This means that innovation is not just the task of a certain department, but of all of a company's divisions. The culture of solution-oriented and flexible creativity must be lived on all levels. This consciousness has been anchored at Swiss Steel for many years.

The successful implementation of new solutions requires in-depth knowledge and the optimum use of existing technical possibilities along the entire process chain, starting with reception and the HR department and all other processes and extending to the freight forwarder and beyond. This also includes close cooperation with the customer. 
Practical examples reveal that both, the company and its customers, benefit when advantageous solutions are based on the existing knowledge as well as the technical means available. In the first example, the customer requires special material properties to save the annealing step in its process chain. This could be reached by adapting the rolling process. In the second case, an innovative highstrength steel for cold forming was introduced. Nuts made of this material exhibit up to $30 \%$ weight reduction and save carbon dioxide emissions. The last example shows the improved friction behaviour of a newly developed graphitic steel in a cutting process.

The development of entirely new material concepts will allow future applications of steel that are seemingly unattainable today. This is the vision we pursue.

\section{References}

[1] L. Chabbi, U. Urlau, O. Lötscher, S. Klein, C. Kaufmann, International Science Technology Congress, Moskoc, Russia, 2014, pp. 371-377

[2] L. Chabbi, Freiberger Forschungsheft, B 315, 2001, ISBN 3-86012-149-9

[3] L. Chabbi, A. Stüber, U. Urlau, P. van Hüllen, MEFORM 2003, Freiberg, Germany, 2003, pp. 232-246

[4] P. Braun-Angott, H. Rohloff, Steel Research, 64 (1993) 7, 350-355

[5] R. Kuziak, S. Zając, R. Kawalla, S. Waengler, K. Stercken, J. Noack, M. Safi, R. Jakubczak, R. Urlau, S. Hasler, L. Chabbi, Cold heading quality low-carbon ultra-high strength bainitic steels (Coheadbain), Final Report, Research Fund for Coal and Steel, Contract No RFSR-CT-2005-00031 (2008)

[6] S. Hasler, Stahl und Eisen 134 (2014) 8, 58-60

[7] R. Züst, S. Hasler, L. Kertesz, P. Unseld, Ecodesign von Stahlkomponenten, Swiss Steel Internal Report (2016)

[8] P. Unseld, L. Kertesz, S. Hasler, Lightweight design of fasteners produced by cold-forming, 13th International cold forming congress, Glasgow, 2015, pp. 94-102

[9] R. Neugebauer, K. D. Bouzakis, B. Denkena, F. Klocke, A. Sterzing, A. E. Tekkaya, CIRP Annals-Manufacturing, Technology 60 (2011) 1, 627-650

[10]J. Rech, P. J. Arrazola, C. Claudin, C. Courbon, F. Pusavec, F. Kopac, CIRP AnnalsManufacturing Technology 62 (2013) 1, 78-82

[11]H. Roelofs, N. Renaudot, D. Smolenicki, J. Boos , F. Kuster, THERMEC Conference, Graz, 2016 